\title{
EL ENFERMO MENTAL EN EL SIGLO XV EN ESPAÑA. CONCEPTUACIÓN COMO ENFERMO DISTINTO Y CURABLE. SU CUIDADO.
}

\author{
Francisco Ventosa ESQUinaldo. \\ Ciudad San Juan de Dios. Autovía Sevilla- Málaga, Km. 15. 41500- Alcalá de Guadaira (Sevilla)
}

\section{RESUMEN}

En este articulo se persigue la contextualización de las tendencias que durante el siglo XV polarizaron las ideas que existían sobre la enfermedad. Asimismo, en este estudio se refleja la importancia del concepto de locura y la del loco o alienado como enfermo psíquico y todo ello relacionado con los cuidados psiquiátricos.

\section{PSYCHIC -SICK- PACIENT IN THE XVTH CENTURY IN SPAIN. CONCEPT OF THIS PACIENT AS DIFFERENT AND CURABLE. ITS CARE.}

\section{SUMMARY}

This article gives us the tendences that existed in the XVth century. about the ideas of sickness, because this was the epoch of transition between medieval and modern world. It shows us the importance of the historical evolution of the concept madness and the consideration of the mad-person as a psychi-sick-pacient in relation to the evolution of psychiatric cares.

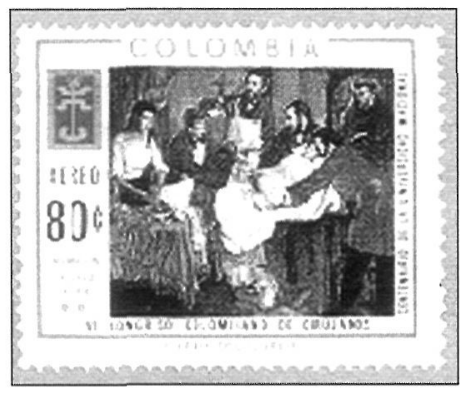

\section{A MODO DE INTRODUCCIÓN}

Desde que el hombre ha aparecido en la tierra hace millones de años no ha hecho otra cosa que afrontar problemas: el de sobrevivir, la convivencia, el conocimiento, el amor, el enriquecerse, la autoafirmación, la felicidad, la muerte. En esta continua búsqueda de soluciones, que han comportado grandes conquistas y, al mismo tiempo, grandes ruinas, el desarrollo de la persona humana ha sido la constante de cuantas generaciones de hombres nos han precedido.

Aunque han existidó momentos de duda, de regresión y barbarie, es innegable que la humanidad ha centrado sus esfuerzos principales orientados a un proceso de liberación individual y social tanto de anarquías internas o de presiones externas.

El sentido de la vida, de la existencia, expresan de alguna manera la religiosidad de cada pueblo y de cada persona. Quien piensa que su vida y la de sus semejantes carece de sentido no sólo es un desdichado, sino que apenas es capaz de vivir. En la búsqueda de respuestas sobre el significado de la existencia, la Historia está llena de felices intuiciones, y de prejuicios y de errores que han tenido un peso enorme en la cualidad de la vida humana, de sus aspiraciones y comportamientos.

El hombre y la mujer ha conseguido organizar el saber, la política del trabajo, leyes que comportan sentimientos morales de justicia, de solidaridad. La persona es compleja, misteriosa, rica en sus dimensiones; no podemos reducirla a un sólo nivel, aunque se trate del sobrenatural.

La historia de cada generación no termina en ella misma, sino que, por el contrario, lega a los descendientes, a través de los tiempos, el libro de sus acciones. Adquiere así el desarrollo humano una gravedad y una tensión que imposibilita el azar. Causa y efec- 
to es la razón ultima de todo, siquiera la causa de un resultado se nos escape a una consideración pasajera; pero cuando ahondamos en ella, encontramos siempre la bondad o maldad del pasado que gravita sobre el presente.

Decir que algo ha sido un azar desafortunado es una de las formas más frecuentes de eximirse de la cansada obligación de examinar sus causas: cuando oímos decir que la Historia de la Enfermería es una sucesión de accidentes, podemos sospechar la presencia, en aquellos que lo somos, de cierta pereza mental o de una corta vitalidad intelectual.

En la Edad Media el concepto de asistencia social se desconocía totalmente; predominaba exclusivamente la beneficencia privada. La caridad, virtud cristiana, era practicada por los mejores, pero con carácter individual. Cada hombre y mujer en particular tenía el deber como cristiano de socorrer a su prójimo necesitado; pero estos mismos hombres y mujeres reunidos no se sentían en la propia obligación; el Estado no reconocía a ningún necesitado el derecho a pedirle socorro en sus males. Los desvalidos acudían a la Iglesia; no era competencia del trono el socorrerlos y consolarlos. Cada cual hacia el bien siguiendo sus inspiraciones individuales; se fundan obras pías con este o aquel objeto por los reyes; pero como cristianos, no como Jefes de Estado. Actuaban por impulsos caritativos, lo mismo que podía hacerlo el noble, el mercader, o cualquier ciudadano.

La Iglesia destinaba gran parte de sus bienes al socorro de las necesidades, el clero pedía limosnas por sí, o por sus delegados, para distribuirla entre los pobres, o fundar establecimientos de beneficencia. La Iglesia llegó a considerarse, y la consideraron todos, como la única consoladora de los males que afligían a la humanidad doliente y desvalida.

Michel Mollat ha dado para la Edad Media una definición de pobre que puede considerarse como valida para todas las épocas: A El pobre es el que, de forma permanente o temporal, se encuentra en una de debilidad, de dependencia, de humillación, caracterizada por la privación de medios, variable según las Épocas y las sociedades, de poder y de consideración social: de dinero, relaciones, influencia, poder, calificación técnica, nacimiento honorable, vigor físico, capacidad intelectual, libertad y dignidad personales.
Viviendo al filo de cada día, no tiene ninguna oportunidad de elevarse sin la ayuda de otro (Christophe, 1989).

Basada en la enseñanza de los padres griegos y latinos, se desarrolló una tradición del servicio de los pobres: asistencia a los hambrientos, defensa de los oprimidos, liberación de los cautivos, creación de las matriculas y de los Domus Dei. El obispo es el defensor de los pobres y la hospitalidad monástica conoce un desarrollo espectacular. Los bienes eclesiásticos constituyen el patrimonio de los pobres. La jerarquía eclesiástica admitía los dones de los fieles. Los pobres se ven asistidos y encuentran su lugar en una pirámide de ordenes que pasa por ser la estructura ideal de la ciudad terrena. A finales de la Edad Media se observan ciertos comportamientos especiales con los pobres. Por un lado, la virtud de la pobreza se presenta como un ideal y los pobres, identificados con Cristo, son considerados como los intercesores privilegiados ante Dios. Por otro lado, la pobreza se comprende como una maldición. Degrada al hombre y mujer. Los pobres resultan sospechosos. Dan miedo. Las disputas de los monjes mendicantes el ideal humanista, el espíritu mercantilista, el gran número de vagabundos, las preocupaciones sanitarias, el interés por el orden público, todo esto se conjugó para dejar asentado que los pobres representan un peligro para la sociedad. El mendigo, delincuente en potencia, es comparado a menudo con el malhechor. Se tolera al pobre conocido, se detesta al vagabundo. El número creciente de pobres es un motivo de inquietud. Se intenta ponerles un signo exterior de reconocimiento para establecer cierto control. La carga aplastante de los pobres llegó a superar con mucho las posibilidades de la limosna tradicional.

De una experiencia religiosa que en el pasado santificaba la pobreza, se pasa a una concepción moral que la condena. El pobre que pide limosna por las casas, por las calles y en las puertas de las iglesias, deja de ser un personaje familiar y se convierte en un ser anónimo inquietante, en el semillero de toda clase de desórdenes. En un proceso que se había originado en el siglo XVI la valoración de la pobreza deja de efectuarse desde una perspectiva individualista propia de las zonas rurales, y se percibe como el desamparo colectivo de la ciudad bien notorio en el siglo XVI (González Duro, 1994). 
A la llegada al trono de los Reyes Católicos la situación no podía ser más crítica. Se había roto la solidaridad entre los individuos y los grupos. La Edad Media, en su entraña política, es toda ella el esfuerzo por encontrar un orden para la sociedad en el cual se agrupen en sus respectivas esferas jurídicas, económicas y políticas, los individuos todos. Y ese orden se había roto, había saltado en pedazos y era preciso restablecerlo. Fueron, los Reyes Católicos, grandes celadores de la religión, de alto y valeroso corazón; sufrieron con buen semblante las adversidades que les vinieron y recibieron con gran templanza las prosperidades y victorias que tuvieron. Fueron de gran consejo y providencia, así en las cosas presentes como en las venideras, para que no les hallase desapercibidos; amaron mucho la justicia y todo genero de virtudes, honrando y favoreciendo con palabras y obras a los que las poseían. Fueron de gran veneración en sus personas, en particular la Reina; oían ordinariamente con gran benignidad y mansedumbre a sus vasallos. tuvieron en su consejo y oficio cerca de sus personas hombres insignes y número conveniente; tuvieron gran casa y Corte acompañada de Grandes varones principales, a los cuales honraron y sublimaron conforme a la calidad de su grado... Cuando se ofrecía ocasión tenían memoria de hacerles merced, con todos andaban satisfechos y deseosos de servir en el Gobierno del reino y de su Consejo. Tuvieron más atención de poner personas prudentes y de habilidad para servir, aunque fuesen medianas, que no personas grandes y de casas principales. En su hacienda pusieron gran cuidado como en la elecciln de personas para cargos principales de gobierno, justicia, guerra y hacienda; $y$ si alguna elección se erraba al punto lo enmendaban, no dejando crecer el daño... Despachaban los negocios con toda brevedad, teniendo día señalado para esto; para los demás negocios hacían andar a los Ministros y oficiales con gran cuidado para que los vasallos no recibiesen detrimento ni gastasen su hacienda ni tiempo en dilaciones (Cepeda Adán, 1956).

Galíndez de Carvajal nos dice más sobre los Reyes Católicos en sus Anales Breves: en su hacienda pusieron los Reyes gran cuidado -escribe-, así como en la elección de personas para cargos principales de gobierno, de guerra y de justicia, y si alguna elección se erraba, que sucedía pocas veces, al punto la enmendaban, no dejando crecer el daño, sino remediándolo con justeza... Y para estar más prevenidos en las elecciones, tenían un libro, y en el la memoria de los hombres de más habilidad y mento para los cargos que vacasen, y lo mismo para la provisión de obispados y dignidades eclesiásticos (Beneyto, 1961).

Cuando los pueblos van a comenzar una era nueva en su historia se produce siempre esa ruptura de los cauces normales y ese anhelo de un orden que supone supervivencia y continuidad.

En España durante varias décadas del siglo XV, se sigue anhelando el orden medieval, pero según se vuelve a ese orden medieval, con Fernando e Isabel, y luego con su nieto el Emperador, se va creando en una lenta transformación un orden nuevo.

La autoridad de los Reyes hacia que: todos los hombres, de cualquier condición que fuesen, nobles y caballeros, plebeyos y labradores, ricos y pobres, flacos o fuertes, señores o siervos, en lo que tocaba a la justicia todos fuesen iguales.

Aquella sociedad de los Reyes Católicos comenzaba a sentir, muy débilmente, nuevas preocupaciones. No es que fuera a romperse el molde ideal, pero las reformas que se emprenden llevan ahora una distinta significación temporal. Los elementos nuevos procedentes de otras capas que no son la nobleza imprimen un suave giro a aquella pirámide medieval, aunque sus frutos tardaran siglos en producirse.

El Renacimiento exalta como valor supremo al hombre, y este humanismo constituye la esencia de la forma política española de Isabel y Fernando. El hombre pasa a ser el centro de interés y hacia él convergen todas las manifestaciones del hombre mismo. Ciertamente que el Renacimiento, en cuanto que con esta palabra designamos un período concreto de la Historia Europea, cuyos límites cronológicos varían de un país a otro, pero que, en principio, empieza a presentarse, unido a influencias italianas, a mediados del siglo XV, para desenvolverse en el XVI.

La transición entre la Edad Media y la Moderna esta ligada íntimamente a la lucha de las ideas dominantes, en cuanto se refiere a la asistencia de los enfermos. El siglo XV es la época de transición entre los mundos medieval y moderno. El mundo medieval 
se había esclerosado, el cristianismo había perdido su espíritu original de forma que los rituales habían suplantado la fe y el mundo secular estaba regido por un sistema complejo y estático de estereotipos tradicionales cuya complicada rigidez quedaba bien simbolizada en la ultima arquitectura gótica. En la mente del hombre aun existía el mundo sobrenatural, pero había perdido vitalidad.

La enfermedad es por esencia un mal físico para quien la sufre, y por tanto para la sociedad; pero la actitud ante la enfermedad cambia con el carácter del enfermo y con la Índole del grupo social a que éste pertenece. La creciente estimación de la existencia terrena, rasgo característico de la vida humana durante los siglos que solemos llamar modernos, da lugar a una mutación considerable en la estimación personal y social de la enfermedad, en tanto que posible preludio de la muerte. Frente a la idea medieval de la enfermedad como un evento nivelador, por una parte, y el menosprecio del mundo de la ascética del medievo, por otra, se levanta ahora, cada vez más acusadas, el ansia de vivir sobre la tierra y la conciencia de que el arte de dirigir la vida propia puede ayudar eficazmente al logro de este fin. Era frecuente los procesos febriles, fiebres erráticas, cuartanas, tercianas y fiebres cotidianas; los trastornos psíquicos, denominados frenesí y melancolía; los padecimientos oculares, el romadizo y el dolor de costado, la hidropesía y los males que exigían la intervención del cirujano, además dolencias pestilentes, el sarampión y la viruela, el fuego de San Antón, o ergotismo, la lepra y sobre todo la peste.

Los enfermos que acuden al hospital no son gentes acomodadas económicamente, estas pueden permitirse el ser atendidas en su domicilio cuando caen enfermas (Ventosa Esquinaldo, 1981). Por tanto la clientela del hospital se caracterizará por su pobreza. Si bien esto sigue siendo válido, se observa una progresiva delimitación dentro del grupo de gentes atendidas, lo cual nos lleva hacia la misma dirección que el resto de las actitudes sociales cara al pobre a que nos referíamos anteriormente. Los reyes, nobles y adinerados, eran atendidos en sus palacios por médicos de cámara y enfermera palaciega, elegidos entre los profesionales más prestigiosos.
La burguesía en sus domicilios, el profesional era amigo o aquel que podía pagar. El pueblo consideraba que la curación de los enfermos era una reconciliación con el demonio, y este concepto de los demonios de la enfermedad, se extendió progresivamente, reconociéndose en la persona del Diablo la más poderosa de las influencias en los poseídos, cuya curación sólo podía lograrse con la expiación. La magia, la magia demoníaca los hechiceros y astrólogos muestran una íntima conexión y en el movimiento histórico se puede percibir la transición entre la magia pagana y la demonología, cuyo resumen lo constituyen los procesos de la Inquisición contra los endemoniados y hechiceros. No está de más señalar que los Tribunales de la Inquisición española fueron infinitamente más humanos que los franceses, italianos y alemanes, siendo los primeros en reconocer y considerar que estas sectas de embrujados no eran otra cosa que grupos de sujetos afectos de trastornos mentales (Gorriz, 1936). Tanto si la locura se consideraba durante la Baja Edad Media como resultado de una crisis emocional o como de una posesión diabólica, el adecuado cuidado del individuo enfermo era asunto que competía a la comunidad. El principio humanitario de que los locos son enfermos y además nuestros hermanos y que hay que tratarles humanitariamente, pues no sabemos si nosotros mismos o nuestros parientes podemos correr la misma suerte, tuvo favorable acogida (Gómez Moreno, 1950). Los intentos para comprender y abordar la enfermedad mental han marcado amplios aspectos de nuestra civilización ya que este tipo de trastorno afecta la íntima esencia de la naturaleza humana y todos nosotros estamos estrechamente involucrados en el problema de la salud mental. La evolución de la asistencia psiquiátrica ha constituido un aspecto fundamental de la evolución de la civilización misma.

Los dementes eran atendidos en los hospitales al igual que el resto de los peregrinos y pobres acogidos (PROVINCIA RELIGIOSA DE CASTILLA, 1965). El enfermo -el loco es quizás uno de los casos más claros del momento- va a dejar paulatinamente de ser considerado como pobre por el simple hecho de padecer una dolencia. Esa tendencia a la diferenciación entre los "pobres enfermos" y los "enfermos pobres" se encuentra ya claramente formulada en la 
zonceptualización de la locura como algo distinto y sanable, si bien es preciso decir que esa posibilidad de curación está marcada en muchos casos por el hecho mismo del carácter clínico de la enfermedad, que registra períodos en que parece haber desaparesido (Piles Ferrando, 1996).

Seria en exceso simplista decir que el hospital utiliza al pobre y al enfermo como un mero objeto, o que es sólo un instrumento económico y de control social, revestido de un rostro caritativo que no es otra cosa que pura apariencia. Es todo eso, pero también es el lugar en donde se realiza un progresivo avance en los cuidados, y en la teoría sobre la enfermedad (López Alonso, 1986).

Una de las manifestaciones significativas del deseo de eficacia y rentabilidad de los últimos tiempos medievales es la reunión y concentración de los establecimientos hospitalarios. Ya en el siglo XV se producirá una nueva fase consistente en un movimiento integrador de la multiplicidad hospitalaria bajomedieval. Este movimiento se va a reflejar en la creación, promovida casi siempre por el poder real, de los grandes hospitales generales. Tres aspectos caracterizaran esencialmente la visión renacentista del hospital, su nueva arquitectura, la incipiente dedicación exclusiva de sus servicios a un fin especializado y la también incipiente ordenación más o menos, centralizada, de los varios, a veces minúsculos establecimientos de una misma ciudad en los que se practicaba la asistencia hospitalaria (Lain Entralgo, 1988).La evolución histérica de los cuidados psiquiátricos va unido a la evolución del concepto de locura y a la consideración del loco como a enfermo psíquico. Es preciso recordar que ni siquiera hoy día poseemos un consenso racional sobre la naturaleza de la enfermedad mental: ¿qué es?, ¿Cuáles son sus causas?, ¿Cómo se cura?.

Este reconocimiento de ignorancia influirá forzosamente en las actitudes que adoptemos ante los enfermos a la hora de dar cuidados. La historia de los cuidados psiquiátricos difiere esencialmente de los cuidados médicos y quirúrgicos, porque el hombre siempre ha tenido conciencia de su enfermedad y de dolor físico y ha buscado la ayuda desde los tiempos del medico hechicero, sacerdote...
El hombre ha tenido siempre la enfermedad y ha recurrido y admirado al cuidador. Pero el hombre afectado por la demencia no tenía conciencia de estar enfermo. Su apariencia física sana, no inspiraba compasión y además se le suponía portador de poderes sobrenaturales. Todo esto llevó a la errónea y transcendental hipótesis de que la medicina no tenía objeto ni poder, ni derecho, sobre los enfermos mentales. Estas condiciones animosas de culturas primitivas estuvieron profundamente arraigadas a través de los siglos y han sido los principales obstáculos que han impedido llegar al concepto de la locura como enfermedad y a la consideración del loco como enfermo. Pero hay un aspecto en el momento inicial del siglo $\mathrm{XV}$ que es necesario resaltar: el sentido filantrópico de los españoles y la forzosa convicción publica de que había que mejorar la suerte de los infelices locos, añadiendo el precepto del amor al prójimo, fuerte mandato para los cristianos fervientes en los distintos reinos peninsulares. Lo maravilloso y sorprendente no será la atención hospitalaria a los locos, desfallecidos de seso, orates, dementes, inocentes, furiosos, folls; sino su cuidado diferenciado, su conceptuación como enfermos distintos, y curables.

En este periodo todas las instituciones dedicadas a enfermos mentales se llamaban de inocentes, nombre con que la Iglesia designa y celebra el sacrificio de aquellos menores de edad que sufrieron la muerte por el Rey Herodes. Por analogía eran inocentes los enfermos mentales, ya que habían perdido la luz de la razón, y Casa de Locos, Casa de Orates, Casa de Inocentes eran llamados los hospitales fundados para estos enfermos. El nombre de inocentes tiene un sentido protector del enfermo mental, que sólo el cristianismo supo valorar en toda su amplitud. El concepto romano de locas, furiosas, mentecatas, encajaba en su criterio de clasificación con relación a los actos de la vida jurídica. El concepto posterior de orates, endemoniados y posesos, entrañaba exclusivamente un sentido de peligrosidad y de perjuicio. El sentido inocente expresa mejor la idea caritativa de protección y amparo, con una comprensión más adecuada y justa de lo que es la enfermedad mental (Chueca Goitía et al., 1989). 
$\mathrm{Ni}$ el Estado ni las corporaciones oficiales se creían obligadas a socorrer las miserias de los desgraciados. Dejaban esta función en manos de los ciudadanos; los cuales, impulsados por los sentimientos caritativos, suplían la acción oficial socorriendo al menesteroso, con limosnas o servicios; muchas, ingresando en cofradías dedicadas al ejercicio de la caridad en alguno de sus múltiples y variados aspectos, y otros destinando todo o parte de su patrimonio a la fundación de nuevos hospitales. Cada uno lo hacia sin tener en cuenta las necesidades generales, guiados únicamente por el deber de ser misericordioso y por la simpatía hacia determinadas clases de personas, o por la compasión que les inspiraban los que padecían cierto género de enfermedad; con lo cual, algunas veces ocurría que en la misma localidad existían varios establecimientos destinados a socorrer a una misma clase de enfermos, y, en cambio, no había centro alguno donde asistir otras clases de necesitados. Las fundaciones se hacían sin inspección o normas, pues tanto el Estado como los Corporaciones oficiales se limitaban, a lo sumo, a subvencionar a alguna de estas Instituciones, muchas de ellas resultaban deficientes, y, más tarde, llegaban a ser inservibles por no estar controladas ni en su administración ni en su funcionamiento, malográndose así, en perjuicio de los mismos enfermos, gran parte de los esfuerzos que, por socorrerlos, se imponía aquella sociedad. Por otra parte, los cargos de algunos establecimientos se convierten en verdaderas prevendas. De este modo los recursos se desvían de la atención a los pobres y enfermos. Aunque no haya que generalizar ciertos hechos excepcionales, no hay más remedio que constatar que las instituciones caritativas que legó la Edad Media eran impotentes desde hacia tiempo para socorrer las necesidades de los pobres. Por todos estos motivos la opinión publica a comienzos del siglo $\mathrm{XV}$, reclama la fundación de Hospitales Generales con la fusión, si preciso fuera, de los particulares existentes en una misma localidad. así lo pidieron repetidas veces las Cortes de aquella época, interpretando fielmente el sentir unánime de los pueblos que representaban (Ventosa Esquinaldo, 1994, 1995).

\section{BIBLIOGRAFÍA}

Beneyto, J. (1961) Historia Social de esparza y de Hispanoamérica. Cultura e Historia.

Cepeda Adán, J. (1956) En torno al concepto del Estado en los Reyes Católicos. CSIC, Madrid.

Christophe, P.(1989) Historia de la pobreza. Verbo Divino, Estella-Navarra.

Chueca Goitía, F. et al. (1989) Los hospitales de Sevilla. Real Academia Sevillana de Buenas Letras, Sevilla.

Gómez Moreno, M. (1950) Primicias Históricas de San Juan de Dios. S. Aguirre impresor, Madrid.

González Duro, E. (1994) Historia de la locura en España. Tomo 1. Historia de Esparza sorprendente. Temas de hoy, Madrid.

Gorriz, M. (1936) Historia de la asistencia psiquiátrica. Madrid. Los progresos de la clínica, 291.

Lain Entralgo, P. (1988) Historia de la Medicina. Salvat, Barcelona.

López Alonso, C. (1986) La pobreza en la Esparza medieval. Madrid. Ministerio de Trabajo y Seguridad Social, Madrid.

Piles Ferrando. F. (1996) Dejaos guiar por el espíritu. Curia General, Orden Hospitalaria de S. Juan de Dios, Roma.

Provincia Religiosa de Castilla H.H de San Juan de Dios (1965) Letra viva. Carta y escritos de S.Juan de Dios. Tip. Artística-Alemana, Madrid.

Romeu de Armas, A. (1942) Historia de la Previsión Social en España. Revista del Derecho Privado, Madrid

Ventosa Esquinaldo, F. (1981) Historia de la enfermería española. Ciencia 3, Madrid

Ventosa Esquilando, F. (1994) Antón Martín y el origen del Hospital General de Granada. Index de Enfermería, III, 7: 58-59.

Ventosa Esquinaldo, F. (1995) Juan Ciudad. Reflejos de la personalidad humana de un reformador. Index de Enfermería, IV, 14: 15-18. 